\title{
Institutional Research Units in Higher Education Institutions in South Africa
}

\author{
Nicole Muller, Sipho Langa, Philiswa Dlamini
}

\section{Background}

For the purposes of providing an overview of the scope of IR activities and office set-up, an online survey was distributed to all the Higher Education Institutions (HEIs) in Botswana, Namibia and South Africa who have staff members who are current or former members of the Southern African Association for Institutional Research (SAAIR). We identified twenty-six institutions from the SAAIR membership list, which included public and private HEls. Twelve institutions returned the completed questionnaire (a response rate of $46 \%$ ); the respondents were from South African HEls only. The responses provided a spread across South African HE institutions, namely, three comprehensive universities, four traditional universities, four universities of technology and one private HEI. South Africa's three new universities, established in 2014, were not included in the survey. The geographical distribution and institutional type of responding institutions are shown in Table 1.

Table 1: Institutional types and geographical spread of respondents

\begin{tabular}{|l|c|c|c|c|}
\hline & University & $\begin{array}{c}\text { Comprehensive } \\
\text { Institution }\end{array}$ & $\begin{array}{c}\text { University of } \\
\text { Technology }\end{array}$ & $\begin{array}{c}\text { Private Higher } \\
\text { Education } \\
\text { Institution }\end{array}$ \\
\hline Eastern Cape & $X$ & $X$ & & \\
\hline Free State & $X$ & $X$ & $X$ & $X$ \\
\hline Gauteng & $X$ & $X$ & $X$ & \\
\hline KwaZulu-Natal & & & & \\
\hline Limpopo & & & $X$ & \\
\hline North West & & & & \\
\hline Western Cape & $X$ & & & \\
\hline
\end{tabular}

It is important to keep the limitations of this research in mind. Firstly, the responses included in this chapter are from South African HEls only. A second limitation relates to the time in which the survey was distributed. This was a few weeks before student protests (the 'Fees Must Fall' campaigns) in South Africa began, which disrupted the last part of 2015 and led to the temporary closing of a number of universities. As a result, some institutions indicated they were unable to respond to the survey. Finally, no definition of what constitutes institutional 
research' was provided in the survey, and this led to a wide interpretation by respondents of what functions within an institution were associated with institutional research offices.

The conclusions reached in this chapter cannot be generalised across the South African HE sector, but are limited to the respondent sample.

\section{Structure and Functions of the IR office}

In this section we present an overview of the roles and functions of Institutional Research with reference to the models of Terenzini (1993) and Volkwein (2008). Although the roles in these models are perceived differently - either as three tiers of organisational intelligence (Terenzini 1993 and 2013) or as changing roles for IR depending on purpose and audience (Volkwein 2008), they share a common point of view. Terenzini and Volkwein both concur that the IR role is to provide reliable information and evidence that supports decision making, institutional governance, and quality management. In this chapter we expand on these ideas and other possible considerations.

Lange (2014) describes the mushrooming of institutional research and management information offices at HEls in South Africa, and postulates that this is largely the result of the drive for policy implementation by the state and its agencies. In this process, she says, "a new class of professional managers... have as their responsibility the gathering, interpretation and dissemination of knowledge about the university to be used for reporting purposes, but also as part of the performance management of academics and as steering mechanisms in the implementation of universities' strategic plans" (2014:16).

Although there are differences between the contexts in South Africa and the USA, it is illuminating to consider the results of studies on the scope and nature of IR, given the many similarities in Higher Education between these two countries. A 2009 survey of Institutional Research offices, conducted by the RP Group for the California Community College System, found that this was a "sector in transition". The scope of work expected from the IR offices was on an upward trajectory while relatively new directors with varying levels of research experience led a number of the offices. There was little or no agreement on what the emphasis of the IR office work should be, with some arguing that a core position of reporting should be maintained rather than a shift from reporting to collaborative research (The RP group 2009). The sector also reported increased demands for evidence from a broader range of people without being provided with more support. Offices were having to work with different types of data and having to tailor the findings appropriately for the audience. This was reported to be to the detriment of understanding and integrating research findings into evidence-based decisions and practice. The survey also found that IR staff were looking for training that would equip them to work more effectively with academic staff, with an emphasis on supporting student-learning outcomes.

The recent National Survey of Institutional Research Offices conducted by the Association of Institutional Research (AIR) in the USA (Swing, Jones \& Ross 2016) concurs with the finding of previous similar studies conducted by Volkwein (2008) and the RP Group (2009) that the IR offices spend most of their time on reporting. The AIR 2016 survey also found that, although responsibilities vary from one IR office to another, some of the tasks are common 
across institutions. While the AIR (Swing et al. 2016) findings agree with the studies of Volkwein and the RP Group that there are differences in IR office structures, they also found that, with a few exceptions, there is consistency in size across institutions.

In his study, Volkwein (2008) found that the structure and functions of the IR offices could be categorised into four different models that he calls, respectively, a craft structure, a small adhocracy, a professional bureaucracy and an elaborate profusion. Craft structures consist of one or two staff members who are responsible for the periodic generating of reports and who produce statistics for the institution. A small adhocracy often develops from craft structures and comprises two or three personnel within a flat hierarchy and a simple structure, where staff performs tasks that are dedicated to the departments or units where they are located. He maintains that small adhocracies usually develop into professional bureaucracies with functions being organised formally into a single centralised office. For each of these models, there is an approximate number of associated staff. The fourth model has IR functions/ offices decentralised and spread across the institution, resulting in "elaborate profusion".

The results of the South African survey showed that, out of the 12 respondents, three identified adhocracy as the model that best describes the scope and operations of their IR office. One institution indicated that their IR unit could be best described as a craft structure, and another as elaborate profusion. The majority (seven) indicated that their operations could be characterised as a professional bureaucracy. Five of these seven institutions had a staff of between five and 19, while the other two institutions indicated that they had two or fewer staff members in the IR office. According to Volkwein (2008) and Volkwein et al. (2012), however, the professional bureaucracy usually has a more formal arrangement with more than four professionals dedicated to the IR office. On this basis, therefore, the two South African HEls with fewer than four staff in their IR offices do not qualify to be considered as professional bureaucracies, but it is possible that their single office structure is the reason that they categorised themselves as such. The surprising element is that most of the responding institutions had more than six staff members - a distinct difference to Volkwein's findings on the situation in the USA, and backed up by the AIR (2016) findings that fewer than five full-time equivalent (FTE) staff members staffed $82 \%$ of the American institutions. It is possible, however, that, in the South African survey, this is the result of a conflated group of functions that might not have been interpreted in the same manner by Volkwein's population group. For example, staff responsible for the work related to the Higher Education Management Information System (HEMIS) in South African institutions was typically included in the count of IR staff.

How long have IR offices been in existence in South Africa? According to our respondents, seven institutions have had their IR office in place for more than seven years, while the IR office for four others has been operating for between four and six years, and only one indicated that their IR office has been operating for fewer than three years. Compared to the United States of America, this shows that formal structures for IR are still relatively young in South Africa.

The titles given to IR practitioners include directors/managers, institutional researchers, institutional planning staff, management information staff, quality assurance staff and administration (support) staff. The highest qualification held by the 46 individuals in their IR 
offices reported by our respondents included eight doctoral degrees, 20 master's degrees, 11 bachelor degrees, three diplomas and four matric certificates. In terms of duration of service, ten of those ranked at director level had more than four years' experience, of whom six have more than 7 years' experience. Only one individual at this level has less than three years' experience. This suggests a fairly mature cohort of directors amongst the respondents. The picture of the Institutional Researchers is somewhat different, showing a far larger group of staff (18) who have less than six years' duration, of whom 11 have less than three years' experience. This at least points to a potential pool of future IR leaders, if these individuals are retained in the field of IR.

The distribution of highest qualifications and the duration of service for the IR staff are shown in Table 2.

Table 2: Qualifications and experience of staff members of a selection of IR units in South African Higher Education Institutions

\begin{tabular}{|c|c|c|c|c|c|c|}
\hline $\begin{array}{c}\text { Highest } \\
\text { Qualification }\end{array}$ & $\begin{array}{c}\text { Directors } \\
/ \\
\text { Managers }\end{array}$ & $\begin{array}{l}\text { Institutional } \\
\text { Researchers }\end{array}$ & $\begin{array}{l}\text { Institutional } \\
\text { Planning } \\
\text { staff }\end{array}$ & $\begin{array}{c}\text { Quality } \\
\text { Assurance }\end{array}$ & $\begin{array}{l}\text { Management } \\
\text { Information } \\
\text { Systems staff }\end{array}$ & $\begin{array}{c}\text { Admin } \\
\text { staff }\end{array}$ \\
\hline $\begin{array}{l}\text { Doctoral } \\
\text { degrees }\end{array}$ & 3 & 6 & 0 & 0 & 0 & 0 \\
\hline $\begin{array}{l}\text { Master's } \\
\text { degrees }\end{array}$ & 7 & 12 & 1 & 2 & 0 & 0 \\
\hline $\begin{array}{l}\text { Bachelor's } \\
\text { degrees }\end{array}$ & 0 & 2 & 1 & 0 & 6 & 2 \\
\hline $\begin{array}{l}\text { Honours } \\
\text { degrees }\end{array}$ & 0 & 0 & 2 & 1 & 1 & 0 \\
\hline $\begin{array}{l}\text { National } \\
\text { diploma }\end{array}$ & 1 & 0 & 1 & 0 & 0 & 1 \\
\hline $\begin{array}{l}\text { Matric } \\
\text { certificate }\end{array}$ & 1 & 1 & 0 & 0 & 1 & 1 \\
\hline \multicolumn{7}{|c|}{ Duration of service } \\
\hline $0-3$ years & 3 & 11 & 4 & 1 & 7 & 4 \\
\hline 4-6 years & 4 & 7 & 2 & 0 & 1 & 2 \\
\hline $\begin{array}{l}7 \text { years and } \\
\text { above }\end{array}$ & 6 & 2 & 3 & 2 & 2 & 2 \\
\hline
\end{tabular}

Fincher (1978) viewed the provision of organisational intelligence as one of the functions of an institutional research (IR) office. This idea was further expanded by Terenzini (1993) who distinguished three tiers of organisational intelligence. The first and foundational tier is the provision of technical and analytical intelligence. IR work at this level concerns generating facts and figures about an institution on admissions, enrolment, degrees awarded, faculty workload, instruction/research staff to student ratio, etc. This information is important for a description of the profile of an institution. IR practitioners operating at this level are expected to be familiar with the organisational and governance structures, definitions of terms, calculations, tools, and research. The issues intelligence is Terenzini's second tier. IR work at this level incorporates elements of process and methodology and specifically relates to the challenges facing the institution. These challenges could include resource allocation, 
programme evaluation, setting enrolment targets, faculty evaluation, and facilities planning. Issues intelligence also requires an understanding of the elements of institutional culture such as decision-making processes and how the institution functions. IR work at Terenzini's third level concerns the generation of contextual intelligence. This is high level intelligence relating to the institution's culture and history, how it is contextualised in its external environment, and understanding the external trends impacting upon it.

Using Terenzini's organisational intelligence levels as a framework, we now report the extent of functions performed by professionals in IR offices in South Africa, and we map these reported functions against Terenzini's three levels (Terenzini 1993). We tabulate those functions that were identified by our respondents as the most prominent type of intelligence produced by their office. Respondents were asked to prioritise the most important functions, and to indicate if these functions were (a) the primary functions of the IR Office, or (b) whether they were shared functions between the IR Office and other units or (c) whether those functions were undertaken as a support function in the service of other units in the institution. The highest rated responses are indicated in Table 3 below.

Table 3: Organisational intelligence levels and functions according to degree of responsibility

\begin{tabular}{|c|c|c|c|c|}
\hline $\begin{array}{l}\text { Organisational Intelligence } \\
\text { Level/Function }\end{array}$ & Primary & Shared & Support & None \\
\hline \multicolumn{5}{|l|}{ Contextual Intelligence } \\
\hline Policy formulation & $67 \%$ & $17 \%$ & $8 \%$ & $8 \%$ \\
\hline \multicolumn{5}{|l|}{ Issues Intelligence } \\
\hline Benchmarking & $50 \%$ & $33 \%$ & $17 \%$ & $0 \%$ \\
\hline Student tracking & $58 \%$ & $25 \%$ & $8 \%$ & $8 \%$ \\
\hline Enrolment statistics & $67 \%$ & $17 \%$ & $8 \%$ & $8 \%$ \\
\hline Comparative staffing patterns & $33 \%$ & $50 \%$ & $8 \%$ & $8 \%$ \\
\hline Salary studies & $8 \%$ & $8 \%$ & $25 \%$ & $58 \%$ \\
\hline \multicolumn{5}{|l|}{ Technical/Analytical Intelligence } \\
\hline Administration of student surveys & $50 \%$ & $25 \%$ & $17 \%$ & $8 \%$ \\
\hline Enrolment statistics & $67 \%$ & $17 \%$ & $8 \%$ & $8 \%$ \\
\hline Student tracking & $58 \%$ & $25 \%$ & $8 \%$ & $8 \%$ \\
\hline Retention and graduation rates & $67 \%$ & $8 \%$ & $8 \%$ & $17 \%$ \\
\hline Data administration & $50 \%$ & $17 \%$ & $25 \%$ & $8 \%$ \\
\hline Degree award statistics & $50 \%$ & $17 \%$ & $17 \%$ & $17 \%$ \\
\hline National data contribution & $50 \%$ & $25 \%$ & $8 \%$ & $17 \%$ \\
\hline Survey analysis & $50 \%$ & $42 \%$ & $0 \%$ & $8 \%$ \\
\hline Workload analysis & $58 \%$ & $33 \%$ & $0 \%$ & $8 \%$ \\
\hline
\end{tabular}


These data show that most of the primary functions currently located in South African IR offices can be classified as technical/analytical intelligence (Tier 1). As one ascends to the other two levels, the prevalence of higher levels of intelligence as primary functions decreased significantly.

Volkwein expands on the four typologies discussed above to present what he calls "the four faces of institutional research" (Volkwein 2008). These faces are depicted in the domains of purpose and audience. In the purpose domain, IR staff are expected to play several administrative and/or professional roles. In an administrative role, the IR practitioner is a member of the administration and management team of the institution. The professional role of the work of the IR practitioner is academic and scholarly in nature. In the audience dimension, the IR professional is required to report to both internal and external audiences for formative (internal audience - improvement) and summative (external audience accountability) purposes. IR practitioners are expected to play four roles, that of information authority (expected to describe the institution's shape and size, its students and staff, and its activities) policy analyst (expected to study and analyse the institution and its policies), the spin doctor (expected to present the best case for the institution) and the scholar and researcher (expected to investigate and produce evidence so that institutional effectiveness, legal compliance, and goal attainment can be judged).

In our survey, we requested respondents to rank the functions for which they were primarily responsible. Our approach was to take those functions identified by five or more institutions as the most common and map them against Volkwein's four IR faces. This is illustrated in Table 4. The mapping was guided by Volkwein's description and examples.

From Table 4, it is clear that the focus in South African IR offices is still largely internally focussed on the creation of intelligence for formative purposes to be used in support of institutional improvement. There is a much smaller external focus. It is clear, however, that there is a swathe of roles that are prevalent in all institutions. This is in keeping with the findings of the 2009 study for the University Leadership Council in the USA which found that, "although the responsibilities of IR offices vary across institutions, certain roles are consistent across the board...the most important IR office function is decision support for administrators" (University Leadership Council 2009:3).

Serban (2002) added a fifth face to the four depicted above. This is the IR professional as knowledge manager, where creating and managing knowledge is a form of organisational intelligence that "fertilizes all the others" (Volkwein 2008:37). This fifth face of IR was not evident in our research results. 
Table 4: Primary responsibilities of IR offices, mapped against Volkwein's Four Faces of Institutional Research

\begin{tabular}{|c|c|c|}
\hline \multirow{2}{*}{$\begin{array}{l}\text { Organis- } \\
\text { ational Role } \\
\text { and Culture }\end{array}$} & \multicolumn{2}{|c|}{ Purposes And Audiences } \\
\hline & $\begin{array}{c}\text { Internal } \\
\text { Formative - for Improvement }\end{array}$ & $\begin{array}{c}\text { External } \\
\text { Summative - for Accountability }\end{array}$ \\
\hline 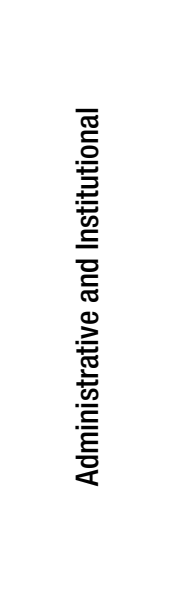 & $\begin{array}{l}\text { 1. IR as information authority } \\
\text { (To describe the institution) } \\
\text { Volkwein: Description of Shape and size; } \\
\text { Students and staff, Activities; } \\
\text { Admissions; } \\
\text { Enrolment; } \\
\text { Faculty; } \\
\text { Degrees awarded; } \\
\text { Descriptive statistics for campus audience. } \\
\\
\text { Survey responses mapped: } \\
\text { Enrolment statistics } \\
\text { Retention and graduation rates } \\
\text { Data administration - provision } \\
\text { Degree awarded statistics }\end{array}$ & $\begin{array}{l}\text { 3. IR as spin doctor } \\
\text { (To present the best case) } \\
\text { Volkwein: Assemble descriptive statistics that } \\
\text { reflect institution favourably; } \\
\text { Describe the glass as half full rather than half empty } \\
\text { Survey responses mapped: } \\
\text { Admissions information } \\
\text { Fundraiser information } \\
\text { National data comparison } \\
\text { Benchmarking } \\
\text { Academic programme review } \\
\text { Degree awarded statistics } \\
\text { Retention and graduation rates }\end{array}$ \\
\hline 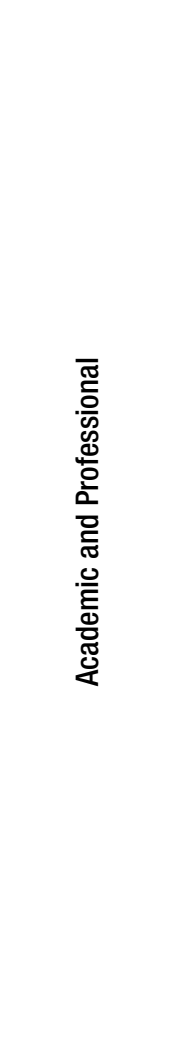 & $\begin{array}{l}\text { 2. IR as policy analyst } \\
\text { (To analyse alternatives) } \\
\text { Volkwein: Study the institution and policies; } \\
\text { Support for planning and budget allocation } \\
\text { decisions, policy revision, administrative } \\
\text { restructuring, other needed change; } \\
\text { Conducts studies in academic affairs, budgeting, } \\
\text { student services; } \\
\text { Studies give alternative enrolment scenarios and } \\
\text { revenue projections; } \\
\text { Comparative cost analysis, student opinion } \\
\text { research; } \\
\text { Studies of salary equity } \\
\text { Survey responses mapped: } \\
\text { Benchmarking } \\
\text { Student tracking } \\
\text { Comparative staffing patterns } \\
\text { Salary studies } \\
\text { Policy formulation } \\
\text { Retention and graduation studies } \\
\text { Student survey } \\
\text { Survey analysis } \\
\text { Workload analysis } \\
\text { Predictive modelling } \\
\text { Learning analytics } \\
\text { Planning } \\
\text { Academic programme review }\end{array}$ & $\begin{array}{l}\text { 4. IR as scholar and researcher } \\
\text { (To supply impartial evidence of } \\
\text { effectiveness) } \\
\text { Volkwein: Impartial researcher and scholar - } \\
\text { investigates, produces evidence for institutional } \\
\text { effectiveness, legal compliance, goal attainment; } \\
\text { Outcomes studies and performance reports to } \\
\text { an external audience; } \\
\text { Accreditation }\end{array}$ \\
\hline
\end{tabular}

Source: Volkwein, 2008 


\section{The institutional location and organisational structure of IR Offices}

In this section we discuss the organisational structure of IR offices. IR offices differ in their reporting arrangements, mix of roles, level in the institutional hierarchy, and work focus. McLaughlin \& McLaughlin identified from their research that "key to the difficulty in precisely defining IR was the fact that each institutional research function tended to take on roles as defined by its institution's needs, desires, and the particular skills and interests of the institutional researcher" (McLaughlin \& McLaughlin 2002:1). This opinion regarding the positioning of the IR office in the organisation structure as a measure of effectiveness and authority is also supported by Leimer who says that "in numerous ways, organizational structure limits the degree to which we can apply our skills on behalf of our institutions" (2009:86). She continues that institutions should consider where institutional research is positioned in the organisational structure so that the capabilities and qualities outlined by her (see later in this chapter) are supported and feed adequately into the institution's learning and improvement. She refers to a number of authors (Ridge 1978; Nichols 1990; Nichols and Wolff 1990; Taylor 1990; Saupe 1990; Billups and Delucia 1990; Lohmann 1998; Bers 2008; Volkwein 2008) who support her contention that "the location of an institutional research office affects its functions and influence, inhibits or facilitates interaction, and can result in acceptance or rejection of its work" (2009:89). The higher an office is placed in the structure, the clearer the signal is of the institution's commitment to the particular activity and sphere of responsibility.

Various titles are used for the offices in which IR is located in HEls. Titles for the IR office in American higher institutions identified by Volkwein (2008:7) include research, institutional research, research and information, research and planning, strategic planning, academic planning and institutional planning. Our respondents indicated that the following titles are used in their institutions: Planning \& Quality Assurance, Institutional Information, Institutional Research and Academic Planning, Institutional Planning \& Research, Office of the Chief Operating Officer, Strategic Management Support, Institutional Planning (three institutions), Research and Innovation, and Institutional Research. Over half the South African respondents (58\%) indicated that the official name of the office responsible for the IR function is the "Planning Office".

IR offices are located at different places within institutions. According to Volkwein (2008:10), "the practice of institutional research tends to be shaped by the part of the organization that it is located in." For example, if the IR office is located in faculties it is very likely to be engaged in studies such as academic workload, salary equity, and research and scholarship on matters of direct relevance to academic staff. On the other hand, if it is located in an institutional or central management environment, it tends to be engaged in the external reporting of institutional data.

Our respondents were asked to indicate their institutional locations and the different levels to which they report. It transpires that, with one exception, these offices report at very senior levels, to either the first or the second tiers of executive management. In contrast, the AIR report (Swing et al. 2016) indicates that half of their respondents report to the chief academic officer, a quarter report to the office of the president and the remainder report to third tiers of management. Examples of the institutional reporting line of IR offices in 
American higher education institutions include Office of the President, Chief Academic Officer, Institutional Effectiveness, Development, Information Technology, Enrolment Management, Business Affairs, and Student Affairs (Swing et al. 2016:5). Our respondents listed the following titles for the offices in which the IR function is located in their institutions (in each case we provide in brackets the number of our respondents who located their IR office in that particular category): Vice Chancellor (2), Deputy Vice Chancellor: Teaching and Learning/Academic (2), Deputy Vice Chancellor: Research and Innovation (2), Deputy Vice Chancellor: Research and Planning (1), Deputy Vice Chancellor: Knowledge and Information Technology Services (1), Senior Director: Policy, Planning and Projects (1), Chief Operating Officer (1) and Chief Information Officer and Executive Director: Quality, Planning and Risk Management (1).

More than half (63\%) of the respondents report at Deputy Vice Chancellor level or higher. This study did not investigate the interesting question whether or not those whose reporting level is lower find that their authority and validity within their institutions is compromised or diminished in any way. We surmise that such units will probably experience diminished levels of influence in their institutions.

\section{Staffing competencies and skills}

The University Leadership Council's 2009 study categorises the staffing competencies and skills set for IR offices into communication skills, analytical skills and technical skills. The report also stresses the importance of continued professional development, citing a number of ways in which this can be achieved (University Leadership Council 2009).

Calderon and Webber (2015b) state that "the ability for IR practitioners to interpret, adapt, and influence policy makers is vital for their ongoing professional success" (2015b:29). There are certain skills and competencies required at institutional and professional/individual levels. In this section we discuss the findings reported in the literature on the skills profiles required for IR professionals using Terenzini's three levels of organisational intelligence $(2013,1993)$. We map the findings of the survey of South African research offices, in respect of skills, knowledge and attitudes of their current IR staff.

The literature shows that the way in which the role of institutional research is seen has progressed in recent times from a data manager to an active agent in and activist for institutional health. Voorhees and Hinds (2012:73) state that "institutional research should serve as the institutional nexus not merely for providing data ... but also ... as the hub for institutional strategy". Borden and Webber (2015:41-53) discuss a variety of options that move IR away from supporting decision making (the pervasive ethos) to a position or mode of contributing to organisational effectiveness.

Leimer (2009:86) contends that Institutional Research can play a role in the transformation of an institution through its contributions to the achievement of the institutional goals. She proposes three main considerations for what she considers to be the 'natural qualities' of institutional researchers, viz. helping to build a broad organisational view, being an active agent in connecting and fostering collaboration, and being a stimulator of organizational learning. For the purposes of our argument, we elaborate briefly on each of these categories. 


\section{a) Fostering a broad organisational view}

Leimer is one of a number of authors who explore the notion of institutional researchers as change agents. If any large scale institutional change is to be brought about, there must be a common vision and shared understanding of the context and major challenges confronting it. For institutional researchers to play a role in the development of a shared understanding and knowledge of the institutional goals, they need to be good communicators and skilled in understanding and communicating with diverse audiences. Examples of these skills include the delivery of written and oral reports, contextualising findings for particular audiences, and reporting findings in a range of forms/media for different audiences. This concurs with the categorization by University Leadership Council (2009:3) of communication skills as one of the set of essential skills required for IR practitioners.

\section{b) Prompting connections and collaborations}

One of the dangers of a silo mentality is that different people and units within the same institution might be attempting to solve the same problems. If IR is seen as a medium for bringing people together to look at a common institutional problem, its practitioners can stimulate collaboration or help to connect people who are working independently of each other. This would require IR practitioners to be skilled facilitators and to have an approach that included systems thinking (2009:88).

\section{c) Stimulating organisational learning}

With increased pressures on universities to be accountable and to be continually improving, there is a need for the use of evidence to underpin decision making. Leimer (2009:88) maintains that by playing this role, IR professionals contribute to organisational learning.

According to Peter Senge (1990:3), a learning organisation is manifested where "people continually expand their capacity to create the results they truly desire, where new and expansive patterns of thinking are nurtured, where collective aspiration is set free, and where people are continually learning to see the whole together". The development of adaptive capabilities as part of organisational learning is supported by Duke (2002:6) who describes organisational learning as "continuously thinking, planning, reviewing, and adapting as an organization." In times of rapid change, only those individuals that are adaptive and flexible are likely to survive. Senge argues that for this to happen, organisations need to "discover how to tap people's commitment and capacity to learn at all levels" (1990:3). Leimer (2009) argues that institutional researchers have a role to play in the process of building a broad organisational view by creating new knowledge and foregrounding insights derived from institutional research (Leimer 2009:89). We contend that Terenzini's levels of intelligence support the concept of a learning organisation that requires that all three intelligence levels be provided by the Institutional Research office, in particular Terenzini's levels 2 and 3 of organizational intelligence, namely issues intelligence and contextual intelligence.

Leimer (2009) states that the three considerations which she calls the "natural abilities of IR practitioners" (discussed above) allow IR practitioners to anticipate stakeholder needs more precisely and timeously. These abilities enable them to provide deeper and richer analyses, to point out the important implications and to formulate relevant recommendations for 
potential change. This articulates well with Terenzini's level of contextual intelligence in terms of which it is the responsibility of institutional researchers to understand the higher education environment as well as the particular institution's culture, history, values and context with the possibility of stimulating change. Terenzini (1993:6) describes this type of intelligence as that which

"reflects organizational savvy and wisdom. It is the crowning form of organizational intelligence... It makes possible the prudent, intelligent, and illuminating application of technical and methodological intelligence to locally meaningful versions of general issues. It represents both content and methodologies tailored to a specific institutional setting where real people are preparing to make real decisions. It is the form of intelligence that earns institutional research and researchers legitimacy, trust, and respect".

Borden and Webber (2015:45) discuss Terenzini's recent (2013) reconsideration of the three tiers that he proposed in 1993. They maintain that while Tier 2 (issues intelligence) is still valid there is a need to enhance knowledge production because of both the changes in technology and increased globalisation. They argue further that Tier 3 (contextual intelligence) requires a greater focus on the external environments at local, national and international levels that may affect a particular institution.

In the previous section, we showed how South African Institutional Researchers view their roles and responsibilities, and we mapped these against Terenzini's three levels of organisational intelligence and Volkwein's four faces of institutional research. Building on that analysis, we now present our respondents' views of the skills, knowledge and attitudes required from IR staff. We compiled a list of 30 competencies and requested the respondents to rank the top 10 of these attributes according to what they consider most important. Their responses were mapped against Ternezini's levels. Respondents were also asked to specify any other attributes that were not on the provided list. These additional competencies from respondents are reflected in the table below in italics. 
Table 5: Staff competencies mapped against Terenzini's levels of organisational intelligence

\begin{tabular}{|c|c|c|c|}
\hline \multirow{2}{*}{$\begin{array}{c}\text { Terenzini's Level of } \\
\text { Organisational Intelligence }\end{array}$} & \multicolumn{3}{|c|}{ Requisite staffing competencies } \\
\hline & Staffing skills & Staffing knowledge & Staffing attitudes \\
\hline $\begin{array}{l}\text { TECHNICAL / ANALYTICAL } \\
\qquad \text { INTELLIGENCE } \\
\text { Analytical } \\
\text { Research design, sampling, } \\
\text { measurement, indicators, data } \\
\text { gathering, indicators, process and } \\
\text { flow modelling, ICT tools } \\
\text { Technical knowledge } \\
\text { Data structures, data elements, } \\
\text { operational definitions }\end{array}$ & $\begin{array}{l}\text { Word processing; } \\
\text { Spreadsheets; } \\
\text { Facility with databases; } \\
\text { Graphics packages } \\
\text { Written and verbal } \\
\text { reporting skills; } \\
\text { Business intelligence skills }\end{array}$ & $\begin{array}{l}\text { Knowledge of quantitative } \\
\text { \& qualitative research } \\
\text { methods; } \\
\text { Statistical techniques \& } \\
\text { analysis; } \\
\text { Factual knowledge of } \\
\text { terminology \& data } \\
\text { definitions; } \\
\text { Knowledge of HEMIS }\end{array}$ & Attention to detail \\
\hline $\begin{array}{l}\text { ISSUES INTELLIGENCE } \\
\text { Process/Procedural } \\
\text { Organisational structure \& culture } \\
\text { Substantive problems } \\
\text { Kinds of issues \& decisions }\end{array}$ & $\begin{array}{l}\text { Making tacit knowledge } \\
\text { explicit }\end{array}$ & $\begin{array}{l}\text { Knowledge of institution- } \\
\text { specific terminology; } \\
\text { Institutional know how } \\
\text { (specific knowledge of } \\
\text { systems, processes, } \\
\text { decision making etc.); } \\
\text { Understanding of the } \\
\text { institutional history; } \\
\text { Understanding of the } \\
\text { institutional culture }\end{array}$ & $\begin{array}{l}\text { Ability to work } \\
\text { collaboratively; } \\
\text { Interpersonal skills; } \\
\text { Ability to work } \\
\text { independently; } \\
\text { Social intelligence }\end{array}$ \\
\hline $\begin{array}{l}\text { CONTEXTUAL INTELLIGENCE } \\
\text { Context of the institution within } \\
\text { external environment }\end{array}$ & Environmental analysis & $\begin{array}{l}\text { Knowledge of HE } \\
\text { environment } \\
\text { Systems approach and } \\
\text { understanding }\end{array}$ & $\begin{array}{l}\text { Ability to work with } \\
\text { ambiguity } \\
\text { Transparent ethos }\end{array}$ \\
\hline
\end{tabular}

Interestingly, the survey also showed that certain competencies were rated by respondents as being less important than those identified in the table above. This is of particular interest, given that some of these competencies and skills may be considered important when we discuss emerging trends in IR (see the next section of this chapter). These include mediating skills, negotiation skills, the skills to conduct environmental analyses and the ability to understand the institutional culture and history.

The comparatively lower ranking of these staff competencies by our respondents makes it clear that South African IR efforts are still largely in the reporting domain, and located in the technical/analytical organisational intelligence level. There appears to be considerable room for an expansion of IR roles and concomitant development of skills to provide a far more pervasive institutional engagement and to play a role as change agents. This issue has turned out to be a recurring question in this book (see Chapter 1)

It is worth noting that over half the respondents $(\sim 53 \%)$ identified a skills deficit in their IR offices and reported a serious need for the enhancement of their current skills. There is a need for opportunities to acquire skills such as modelling, strategic planning, leadership 
skills, curriculum development and academic planning, high-level statistical analysis, and predictive analytics.

In the next section we investigate trends, opportunities and challenges in HE and IR, and, against this backdrop, the question must be considered whether the South African IR practitioners are adequately skilled and prepared for new roles and responsibilities. (In Chapter 5 these concerns are addressed in detail.)

\section{Opportunities and challenges for Institutional Research}

In this section, we consider the trends and future challenges for IR. Universities across the world are faced with changing circumstances and increasing challenges that require new ways of thinking and operating. It is thus appropriate to consider how institutional researchers could position themselves in times of change and uncertainty to assist their institutions to "move ahead with creating actionable data that can spell the difference between being passive recipients of unprecedented change or intelligent actors trying to create a more manageable future" (Voorhees and Hinds 2012: 74). Is it possible for IR practitioners as "intelligent actors" to play an increasingly important and new role in the sphere of organisational intelligence and to add meaningfully to the organisation in a qualitative way?

In the empirical research conducted for this chapter respondents were asked to indicate, against a provided list, what they saw as opportunities and/or challenges for the future of higher education in South Africa. The results are provided in Table 6.

Table 6: Perceived challenges and opportunities in the South African HE environment

\begin{tabular}{|l|c|c|c|}
\hline \multicolumn{5}{c}{ Challenges and Opportunities in the HE Environment } \\
\hline & Opportunity & Challenge & Both \\
\hline Accountability & 4 & 1 & 7 \\
\hline Institutional effectiveness & 2 & 1 & 9 \\
\hline Transformation & 2 & 1 & 9 \\
\hline Access & 5 & 2 & 5 \\
\hline Success & 5 & 3 & 4 \\
\hline Globalisation & 2 & 3 & 7 \\
\hline Competition & 4 & 2 & 6 \\
\hline Sustainability & 4 & 5 & 3 \\
\hline Technology & 4 & 1 & 7 \\
\hline Curriculum & 2 & & 10 \\
\hline Data mining & 7 & & 5 \\
\hline Planning to shape HE & 7 & 1 & 4 \\
\hline
\end{tabular}


The respondents thus see, as both opportunity and challenge, the areas of curriculum, transformation and institutional effectiveness to be the prime considerations going forward. Transformation is indicated by most of the respondents as both a challenge and an opportunity. Curriculum featured highly as well, and, given the nature of the South African student protests in 2015, it is closely tied to transformation, with a call by students to develop post-colonial curricula and to reconsider teaching and learning approaches in the light of such transformed curricula. Likewise, it is not surprising to note that concerns about institutional sustainability and institutional effectiveness rank highly as both challenges and opportunities. Furthermore, globalisation and technology are also moderately considered as both challenge and opportunity. Data mining and planning to shape HE are considered to be significant opportunities. Given these considerations, what are the implications for IR in South Africa?

In contextualising IR in South Africa, Botha (2015) refers to the impact that the transition to democracy has made on South African institutional researchers. He postulates that the possible challenges for institutional researchers going forward include student access and success, the provision of actionable information on the formal and informal (out of the classroom learning) curricula, increased demands for rich data to support enhanced teaching and learning, and greater use of tools to generate and report on organisational intelligence (Botha 2015:198).

The respondents to our survey all indicated transformation as both a challenge and an opportunity for IR offices in the South African HE environment. The question is, is there a role for IR offices to play in the transformation efforts of their institutions?

Calderon \& Webber (2015b:24) state, "IR practitioners are now playing an active and visionary role in and assessing the long-term positioning for institutions and national systems." Badat (2013:299) purports that institutional research and planning are essential to ensure that "a university, which is not entirely or even largely shaped by historical patterns and contemporary currents and pressures ... proactively and consciously shapes its own future." In this light, Soudien (2015:202) poses the questions: "How will the post-apartheid South African university position itself; for what will it make itself available; and what orientation will it take? What clarity of thinking will it provide the country? In the midst of all the options it has available to itself, questioning, engaging, supporting, opposing, what goals will it set for itself? How will it set priorities?" We argue that to support the strategic unfolding and transformation of their universities, IR practitioners have a fundamental role to play. They can do this by providing good evidence to enrich and inform the decisions that are made at all levels in institutions. IR practitioners could be key agents in helping decision makers to reframe problems and challenges by looking at patterns over time and by working in a logical framework. Such an approach can change the way in which the university strives to understand itself in a complex environment. This brings to mind the definition of Institutional Research provided by Calderon and Webber (2015:14), namely that Institutional Research is about "exploring, understanding and explaining the institution for the institution". Importantly, this includes, in the context of transformation, understanding one's own institution's context and undertaking transformation efforts that are relevant to that context. Nel, in Chapter 6 of this book, talks of the importance of IR to contribute qualitatively to 
transformative processes, and that this will require IR professionals to "embrace contextual intelligence... better to understand complex challenges and opportunities".

In support of IR's role in transformation efforts, Leimer is of the opinion that institutional research contributes to the achievement of organisational goals, "even transformation, by helping to foster a broader organizational view, operating as a connector and facilitator of collaboration, and stimulating organizational learning" (2009:92). She also contends that collaborative-based systems and organisational learning "are viewed as the path to the future ...institutional research qualities can help this transformation emerge" (2009:92). IR practitioners can play a vital role by building collaboration, by communicating and explaining institutional information and intelligence to all the relevant decision makers at all levels of the institution, and by guiding decision makers to understand and use this information optimally and responsibly. Building or enhancing an institutional culture of evidence-based decision making could thus be an optimal responsibility of IR practitioners.

Calderon and Webber (2015a:28) state that the more information that is collected, the more complex becomes its management, but that this also provides an opportunity for widening the scope of analysis, and thus for exploring new possibilities and "fostering institutional innovation". Voorhees and Hinds (2012:73) see IR as the potential hub for institutional strategy, as does Nel (see Chapter 6). Given the results of the survey of IR offices reported in this chapter, it appears, however, that while IR practitioners are aware of these trends, the skills, knowledge and attitudes required to make these part of the IR suite of contributions to their institutions, are lacking. Borden and Kezar (2012) discuss a variety of options that move IR away from supporting decision-making (the pervasive ethos) to a position or mode of contributing to organisational effectiveness.

The literature thus shows a progression of institutional research towards a new role as an active agent in, and activist for, institutional health. The results depicted in Table 5 show that various skills, knowledge and aptitude that would be critical for becoming the hub of institutional strategy were ranked fairly low.

What would be required for IR practitioners to take up these opportunities and challenges? Leimer (2012:89) suggests that IR practitioners must shift to becoming knowledge creators, problem solvers and connectors, and in addition to that, to becoming tacticians and change agents. She contends that, for this to happen, IR practitioners need to be able to knit institutional culture and expectations. The IR professional should not only be considered as the provider of primary institutional data, but as a connector, assisting the institution to become proactive and agile, rather than remaining reactive and sluggish, while acting with a high degree of professionalism and integrity. Strategic decisions and transformative efforts can be enriched and improved if those decisions are informed by good evidence, but having also the focused 'knitting' activity that Leimer describes. Nel, in Chapter 6 of this book, talks of the critical importance of developing trust between IR practitioners and decision-makers.

We conclude our discussion of the future role of institutional research with reference to the following challenge issued by Borden and Webber (2015:50): 
"A value in and a need for IR exists in using strategies and techniques to inform and leverage strategic change and organizational learning that can propel change. This is even more important in our global world and the need to consider actions and goals of higher education worldwide. Good organizational intelligence, the type of information that looks both inward and outward, is central to the management of higher education. IR leaders are positioned well to help with these goals".

In order to fulfil these roles, the practice of institutional research in South Africa will have to shift beyond the first level of organisational intelligence, and from the inward looking face of IR to a more proactive and influential role. IR practitioners in South Africa will have to embrace and understand the contextual intelligence challenges to support their institutions optimally.

\section{Conclusion}

In this chapter we have drawn a picture of the size and shape of institutional research offices in the South African region on the basis of a survey conducted during 2015 to which 12 HEls responded. We have shown that IR practitioners are of the opinion that their IR offices are under-staffed and under-skilled. It is clear that there is a high degree of activity in the first level of Terenzini's hierarchy in IR in South African universities, with slowly growing and expanding functions in the other levels. Are we in a state of readiness to take on new challenges and roles? The layered complexities that face higher education across the world are also prevalent in South Africa. These complexities relate to competing demands, increased competition for students and resources, the need for accountability and viability, and relevance and recognition. In all these respects universities are required to walk a fine line. We agree with Calderon and Webber (2015a), however, who see these challenges and worldwide trends as opportunities for institutional researchers, together with the practices of planning and decision support, to strengthen their roles, and to play a role as change agents at institutional and national levels (Calderon and Webber 2015b).

\section{References}

Badat, S. 2013. Theses on Institutional Planning and Research at Universities. South African Journal of Higher Education, 2:295-308.

Borden, V. \& Kezar, A. 2012. Institutional research and collaborative organizational learning, in R. Howard, G. McLaughlin \& W. Knight (eds.). The handbook of institutional research. San Francisco CA: Jossey-Bass, 86-106.

Borden, V. \& Webber, K. 2015. Institutional and educational research in higher education: common origins, diverging practices, in A. Calderon \& K. Webber (eds.). Institutional Research and Planning in Higher Education: Global Contexts and Themes. New York: Routledge, 41-53.

Botha, J. 2015. Institutional research in South Africa in the service of strategic and academic decision support, in A. Calderon \& K. Webber (eds.). Institutional Research and planning in Higher Education: global contexts and themes. New York: Routledge, 184-203.

Calderon, A. \& Webber, K. (eds.). $2015 a$. Institutional Research and Planning in Higher Education: Global Contexts and Themes, New York: Routledge. 
Calderon, A. \& Webber, K. 2015b. Institutional research, planning, and decision support in higher education today, in A. Calderon \& K. Webber (eds.). Institutional Research and Planning in Higher Education: Global Contexts and Themes. New York: Routledge, 21-39.

Department of Education 2008. Report of the Ministerial Committee on Transformation and Social Cohesion and the Elimination of Discrimination in Public Higher Education Institutions. Pretoria: Government Printer.

Duke, C. 2002. Managing the learning university, Philadelphia, Open University Press.

Fincher, C., 1978. Institutional Research as Organizational Intelligence. Research in Higher Education, 8(2):189-192. http:// dx.doi.org/10.1007/BF00992119

Kezar, A. 2005. (ed.). Editor's notes. Organizational learning in Higher Education. New Directions for Higher Education, 131:1-6. http://dx.doi. org/10.1002/he.182

Lange, L. 2014. Rethinking Transformation and Its Knowledge(s): The Case of South African Higher Education. Cristal studies in teaching and learning, 2:1-24.

Leimer, C. 2009. Taking a Broader View: Using Institutional Research's Natural Qualities for Transformation. New Directions for Institutional Research, 143:85-92. http://dx.doi.org/10.1002/ ir.307

Leimer, C. 2012. The art of Institutional Research. North Carolina Association for Institutional Research 2012 WinstonSalem, NC. PMCid:PMC3420878

McLaughlin, G. \& McLaughlin, J. 2002. Training institutional research professionals. International Conference on Teaching Statistics: The Sixth International Conference on Teaching Statistics. Cape Town, South Africa.

Serban, A. 2002. Knowledge Management: The "Fifth Face" of Institutional Research. New Directions for Institutional Research, 113, 105-111. http://dx.doi.org/10.1002/ ir. 40
Shin, J.C. \& Teichler, U. 2014. The Future of the Post-Massified University at the Crossroads. Restructuring Systems and Functions. Springer.

Soudien, C. 2015. Thinking at the interface: theory and practice in the South African university/community relationship. South African Journal of Higher Education, 29:201-207.

Swing, R.L., Jones, D. \& Ross, L.E. 2016. The AIR national survey of Institutional Research Offices. Tallahasee, FL: Association for Institutional Research.

Terenzini, P. T. 1993. On the nature of institutional research and the knowledge and skills it requires. Research in Higher Education, 34:1-10. http://dx.doi. org/10.1007/BF00991859

Terenzini, P.T. 2013. 'On the nature of Institutional Research' revisited: Plus ca change...? Research in Higher Education, 54:13-1487. http://dx.doi.org/10.1007/ s11162-012-9274-3

The RP Group 2009. Survey of Institutional Research offices in the California Community College System. Sacramento, CA: The RP Group.

University Leadership Council 2009. Institutional Research offices: responsibilities, administrative organization, and staffing structures across six public research institutions. Washington, DC: The Advisory Board Company.

Volkwein, J. 2008. The Foundations and Evolution of Institutional Research. New Directions for Institutional Research, 141:5-20. http://dx.doi.org/10.1002/ he. 289

Volkwein, J., Liu, Y. \& Woodell, J. 2012. The structure and functions of institutional research offices, in R. Howard, G. McLaughlin \& W. Knight (eds.). The handbook of institutional research. San Francisco CA: Jossey-Bass, 22-39.

Voorhees, R. \& Hinds, T. 2012. Out of the box and out of the office: institutional research for changing times, in $\mathrm{R}$. Howard, G. McLaughlin \& W. Knight (eds.). The handbook of institutional research. San Francisco CA: Jossey-Bass, 73-85. 